\title{
Propellant Combustion Wave Studies by Embedded Thermocouple and Imaging Method at Ambient Pressure
}

\author{
Rakesh Kumar Kalal 1,*, Himanshu Shekhar ${ }^{1}$, Prashant Sudhir Alegaonkar², Shrikant Pande ${ }^{1}$
}

Kalal RK iD https://orcid.org/0000-0002-6810-547X

Shekhar H (D) https: / / orcid.org/ 0000-0002-9403-4070

Alegaonkar PS (iD https: / /orcid.org/0000-0002-4670-1684

Pande S (D) https://orcid.org/0000-0002-2467-0653

\section{How to cite}

Kalal RK; Shekhar H; Alegaonkar PS; Pande S (YYYY) Propellant Combustion Wave Studies by Embedded Thermocouple and Imaging Method at Ambient Pressure. J Aerosp Technol Manag, v.12: e1720. https://doi.org/10.5028/jatm.v12.1109

ABSTRACT: This paper discusses the method for propellant combustion studies with embedded thermocouple and imaging method at ambient pressure. In this study, three different propellant compositions are experimentally evaluated for surface temperature, flame zone temperature with embedded thermocouple, and reaction zone thickness with high-speed imaging of propellant during combustion at ambient pressure. Preheat zone and flame zone temperature profiles are recorded with time and surface temperature is determined with available models. Observation of these experiments gives the difference between combustion mechanism of double-base propellant with diethylene glycol dinitrate (DEGDN) and 2,4-dinitrotoluene (DNT), composite propellant (CP) and CP with energetic binder. Scanning electron microscope (SEM) images analysis for pristine and quenched sample is also presented.

KEYWORDS: Combustion; Combustion wave; Thermocouple; Composite propellant; Double-Base propellant.

\section{INTRODUCTION}

Solid rocket propulsion contains propellant as energy source. Solid rocket motor works as chamber for combustion and storage. Propellant generates hot gases within the motor after suitably ignition. These gases are ejected by nozzle at very high velocity and accelerates rocket motor in the opposite direction by imparting momentum. Presently, various types of solid propellants, i.e. double base, composite, nitramine based, nitrate ester poly ester (NEPE) based etc., are well researched and available (Kuo and Summerfield 1984; Kubota 2002). Suitability of propellant for rocket motor applications depends on its characteristics and are selected accordingly.

Numerous researchers have studied propellant burning behaviour to understand the actual combustion phenomenon. Though plenty of work has been done in this direction and various theoretical models (Kuo and Summerfield 1984; Kubota 2002; Powling and Smith 1962; Sabadell 1963) has been proposed, but still a perfect model, which can explain and give insight of the phenomenon, is not available.

Various techniques (Boggs and Zenin 1978; John et al. 2001; Zarko and Kuo 1994) are employed to study the propellant burning, such as embedded thermocouple (Yao et al. 2014; Miller 1990; Alspach and Hall 1991; Sabadell et al. 1965) to find surface temperature and combustion wave propagation, strand burner method for burning rate, video graphic method for burning rate measurement and surface phenomenon studies etc. Modelling of propellant combustion requires temperature profile data in the reactive region and burning surface temperature

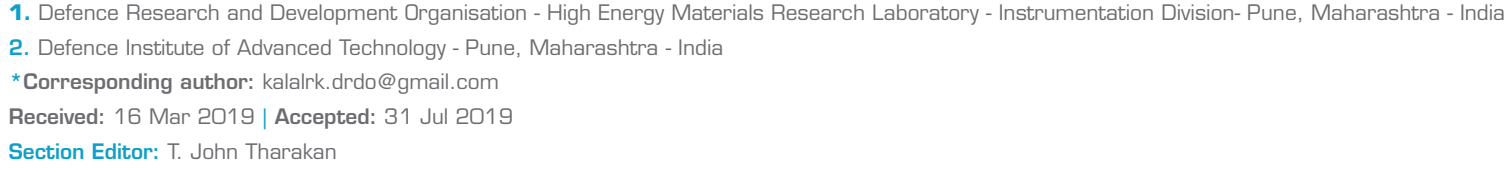


along with other factors such as elementary reaction, reaction kinetics ingredients active species activation energy etc. Various techniques are available as stated earlier and have been successfully implemented to measure these parameters in a combustion environment.

Microstructure studies of propellant surface were performed and well explained for composite propellants (Derr and Boggs 1970). It provides information of self-quenching of ammonium perchlorate (AP), scraggy surface of AP grains, compatibility between AP grains binder, size distribution of AP, 1,3,5,7-tetranitro-1,3,5,7-tetrazocane (HMX), and metal particles etc.

In this paper, studies of different propellant compositions were performed at ambient pressure for combustion wave propagation inside the propellant and high-speed imaging to find the surface phenomenon at the time of burning. Surface phenomenon is explained with scanning electron microscope (SEM) images of pristine and quenched samples. Selected composition was doublebase propellant (DBP) with diethylene glycol dinitrate (DEGDN), 2,4-dinitrotoluene (DNT), composite propellant (CP), CP with energetic binder and HMX.

\section{MATERIALS AND EXPERIMENTAL SETUP}

Double-base propellant with nitrocellulose (NC), DEGDN and DNT (Composition 1), composite propellant with AP 68\%, $\mathrm{Al}$ 18\%, binder and other additives 14\% (Composition 2) and composite propellant with AP 36\%, HMX 21\%, Al 14.4\%, Zr 3.6\% and energetic binder 25\% (Composition 3) were selected for experimental purpose.

An experimental setup, as shown in Fig. 1, was prepared for the measurement of combustion wave propagation through the propellant, flame structure and spreading during combustion. This experimental setup consists of propellant strand with length $\sim 60 \mathrm{~mm}$. Silicon grease layer was applied on all sides of propellant strand to prevent lateral burning. Two C-type thermocouples (tungsten-5\% rhenium and tungsten-26\% rhenium) having 150 microns bead size, response time $\sim 10$ ms, were embedded at a distance of 30-35 mm. These thermocouples were located $\sim 10-15 \mathrm{~mm}$ apart from the end of strand. These thermocouple output was recorded on YOKOGAWA make DL750P ScopeCorder. This recorder has inbuilt conversion table for millivolt output of thermocouples in temperature. It directly displays the temperature with time scale. Data for temperature were recorded at 1000 samples per second. High-speed imaging of burning surface was also performed. AOS-trivit make high speed camera was used for recording images. Images were captured with $12 \times$ optical zoom and 1000 frames per second (fps) during combustion. Propellant strand was mounted on a steady table and ignited with the help of nichrome wire and 24 V, 5A DC power supply. All the experiments were carried out at ambient pressure and temperature.

Scanning electron microscope studies on unburned and quenched sample were performed. Sample were prepared by water quenching after sustained ignition takes place. Samples were kept for $24 \mathrm{~h}$ drying at $40^{\circ} \mathrm{C}$. Unburned and quenched sample were cut in small slice and surface SEM images were generated using Zeiss make scanning electron microscope.

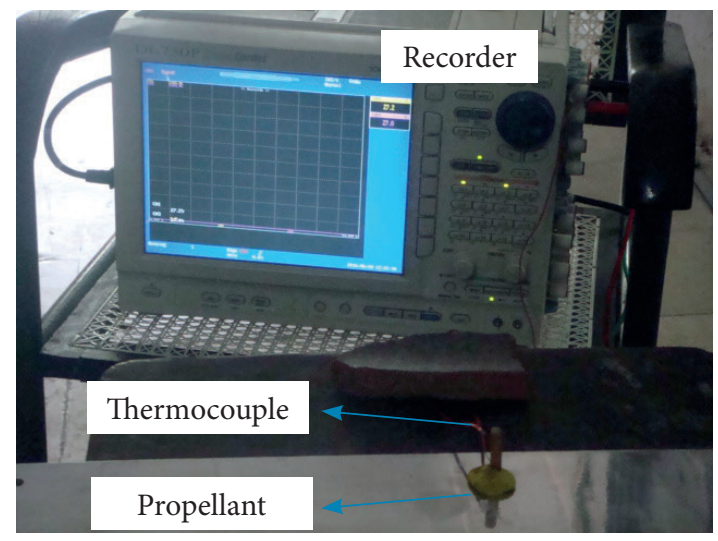

Figure 1. Experimental setup. 


\section{RESULTS AND DISCUSSION}

\section{COMBUSTION WAVE STRUCTURE}

For temperature recording, two thermocouples were embedded in the propellant strand at a distance of 30-35 mm distance as shown in Fig. 2(a). Burning rate at ambient pressure was computed using recorded temperature-time signals. Burning rate and data sampling rate were used to convert temperature-time signal into distance coordinates. A representative temperature-time record for burning rate computation of propellant is shown in Fig. 2(b).

(a)

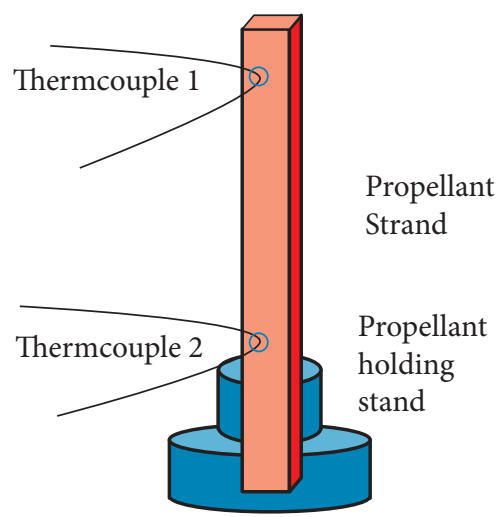

(b)

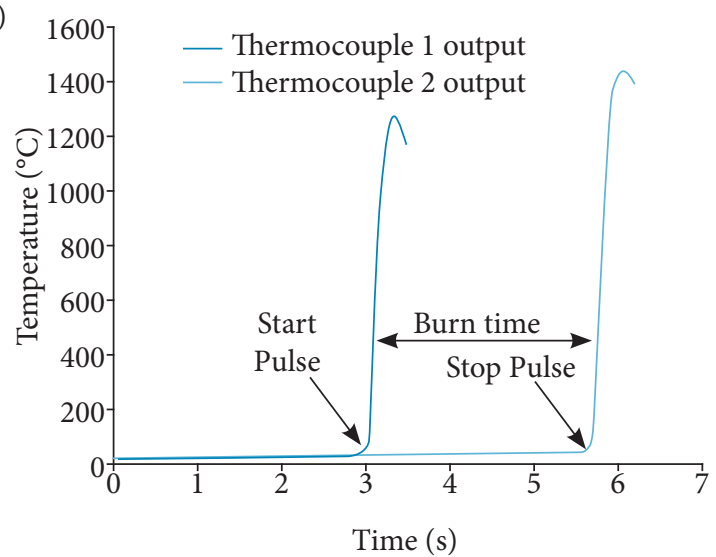

Figure 2. (a) Thermocouple arrangement and (b) temperature-time profile for burn rate.

Burning rate computed with recorded data for Compositions 1, 2 and 3 was respectively 3, 4.33 and $6.6 \mathrm{~mm} / \mathrm{s}$ at ambient pressure. Available technique was used to convert X-axis data to distance burning surface (Alspach and Hall 1991). For this conversion, the propellant burning rate was assumed to be constant and average burning rate data were used. Converted temperature-distance profiles for different propellant compositions are shown in Figs. 3, 4 and 5. For illustrative purposes, data on two experiments of each composition are presented here. Burning surface of propellant was found using available models for surface temperature determination (Alspach and Hall 1991; Sabadell et al. 1965). Table 1 summarizes the surface temperature and flame temperature for representative curves shown in Figs. 3(a), (b), 4 (a), (b) and 5 (a), (b), for the different compositions under study.

Representative temperature profile for two samples of DBP with DEGDN and DNT (composition 1) are shown in Fig. 3 (a) and (b). Surface temperature of this composition is found comparable to nitrocellulose and nitroglycerin based double-base propellant. Average surface temperature (for 8 samples) is $300^{\circ} \mathrm{C}$. Slope $(\mathrm{dT} / \mathrm{dx})_{\mathrm{s}}$ in condensed phase and slope $(\mathrm{dT} / \mathrm{dx})_{\mathrm{g}}$ in gas phase are determined. Slope $(\mathrm{dT} / \mathrm{dx})_{\mathrm{s}}$ is 122.93 and 112.2 for sample 1 and sample 2 respectively, which indicates heat transfer rate in this phase and can be correlated with thermal properties and burning rate of propellant. Heat received by condensed phase from gas phase is related to slope $(\mathrm{dT} / \mathrm{dx})_{\mathrm{g}}$ of recorded data at burning surface (Kubota 1981) and found 104.2 and 136.0 for sample 1 and sample 2 respectively. 
Representative temperature profile for two samples of composite propellant (composition 2) are shown in Fig. 4 (a) and (b). Average surface temperature (for 7 samples) is $460^{\circ} \mathrm{C}$. Slope (dT/dx) in condensed phase is 566.41 and 568.53 . Heat received by condensed phase from gas phase is related to slope $(\mathrm{dT} / \mathrm{dx})_{\mathrm{g}}$ of recorded data at burning surface and found 736.9 and 880.2 for sample 1 and sample 2 respectively (Kubota 1981; Yano et al. 1987).
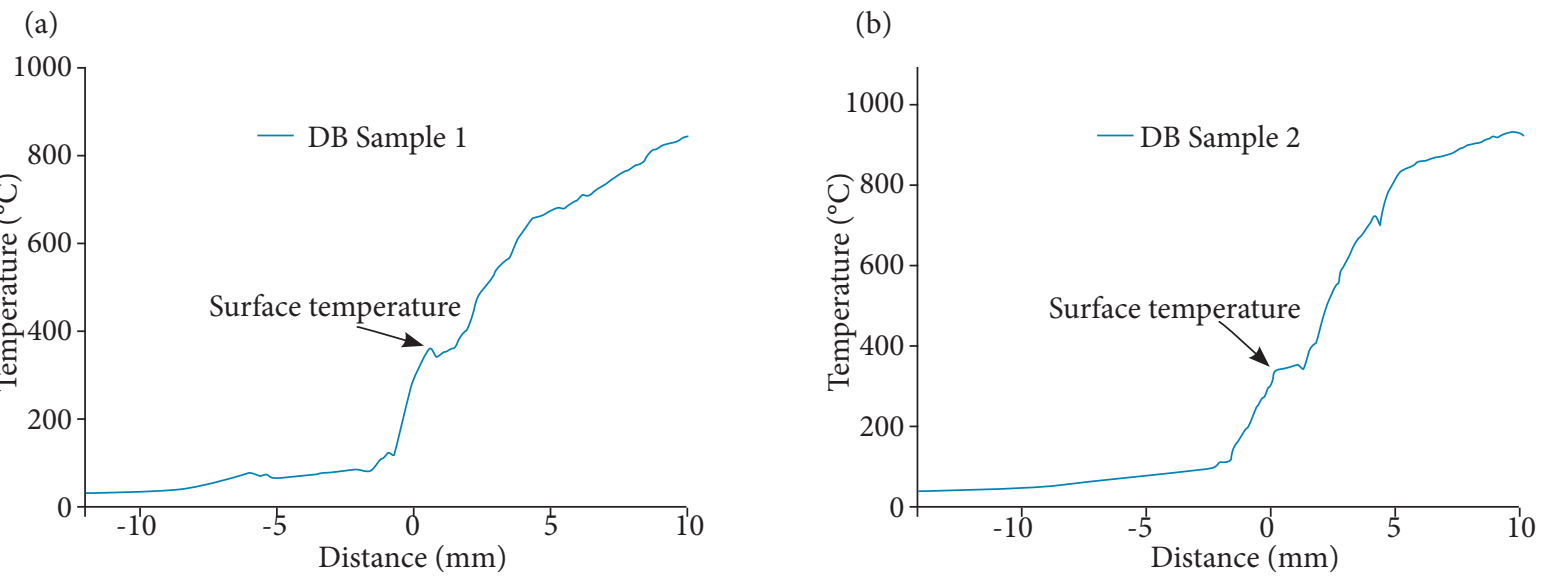

Figure 3. Temperature-distance profile from burning surface for samples 1 and 2 of DBP with DEGDN and DNT.

Table 1. Surface temperature and flame temperature for representative curves for different compositions.

\begin{tabular}{|c|c|c|c|c|}
\hline \multirow{2}{*}{ Composition } & \multicolumn{2}{|c|}{ Surface temperature $\left({ }^{\circ} \mathrm{C}\right]$} & \multicolumn{2}{c|}{ Flame temperature $\left[{ }^{\circ} \mathrm{C}\right]$} \\
\cline { 2 - 5 } & Sample 1 & Sample 2 & Sample 1 & Sample 2 \\
\hline Composition 1 & 292 & 304 & 897 & 945 \\
\hline Composition 2 & 443 & 473 & 1411 & 1667 \\
\hline Composition 3 & 504 & 538 & 1412 & 1600 \\
\hline
\end{tabular}

(a)

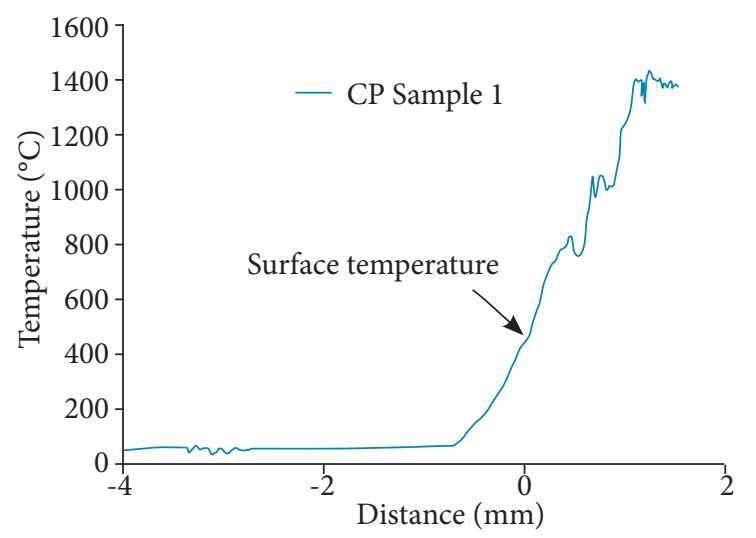

(b)

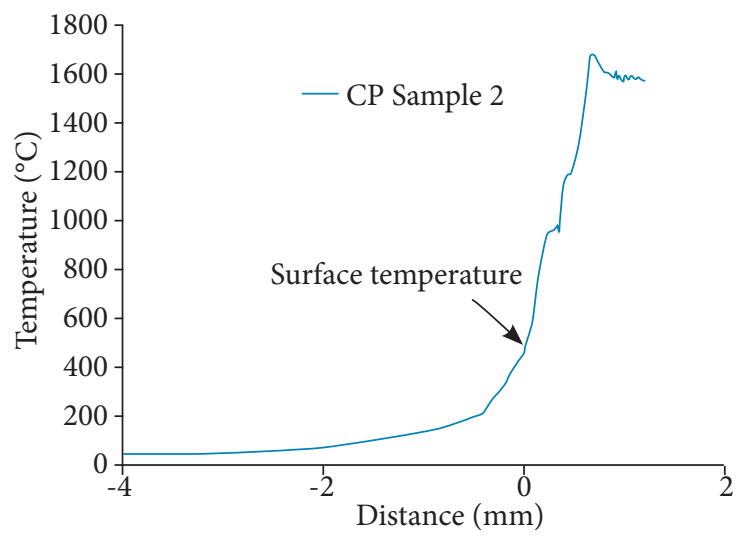

Figure 4. (a) and (b) Composite propellant temperature-distance profile from burning surface.

Representative temperature profile for two samples of composite propellant with energetic binder and $\mathrm{Zr}$ are shown in Fig. 5 (a) and (b). Average surface temperature (for 7 samples) is $537^{\circ} \mathrm{C}$. Slope (dT/dx) in condensed phase is 345.7 and 298.8 . 
Heat received by condensed phase from gas phase is related to slope (dT/dx) of recorded data at burning surface and found 345.1 and 392.6 for sample 1 and sample 2 respectively. Slopes are lower than the composition 2 slopes in both phases, though the burning rate at ambient is higher for composition 3 (Yano et al. 1987). Nitramine base propellant burning rate is dependent on heat released at burning surface with heat feedback from nearby surface (Yano et al. 1987). Also, it may be due to the higher thickness of reaction zone/dark zone, as visible in high speed images.
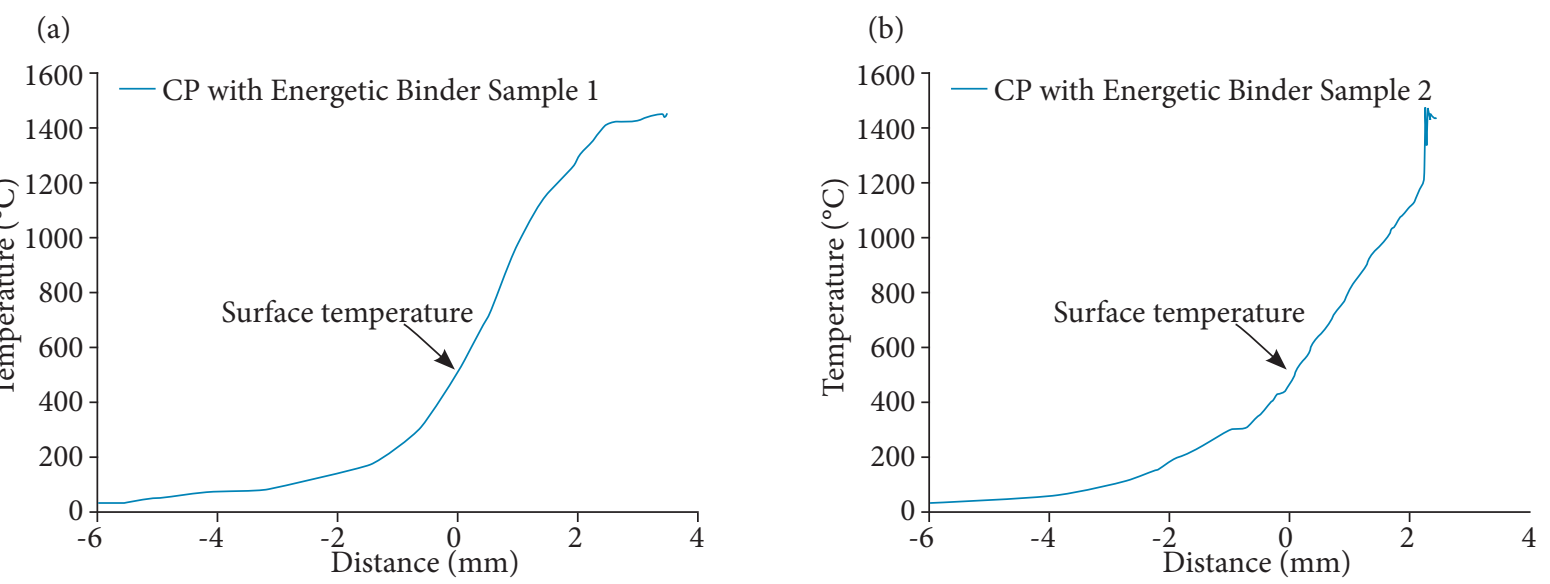

Figure 5. (a) and (b) CP with energetic binder temperature-distance profile from burning surface.

Table 2 shows the data for eight experiments performed during this study. It also indicates deviation in measurement of surface temperature $\mathrm{T}_{\mathrm{s}}$, flame temperature $\mathrm{T}_{\mathrm{f}}$ and Table 3 shows other computed parameters.

Table 2. Surface temperature and flame temperature for different compositions.

\begin{tabular}{|c|c|c|c|c|c|c|}
\hline \multirow{2}{*}{ Test No. } & \multicolumn{2}{|c|}{ Composition 1} & \multicolumn{2}{|c|}{ Composition 2} & \multicolumn{2}{|c|}{ Composition 3} \\
\hline & $\mathrm{T}_{\mathrm{s}}\left({ }^{\circ} \mathrm{C}\right]$ & $\mathrm{T}_{\mathrm{f}}\left({ }^{\circ} \mathrm{C}\right)$ & $\mathrm{T}_{\mathrm{s}}\left({ }^{\circ} \mathrm{C}\right)$ & $\mathrm{T}_{\mathrm{f}}\left({ }^{\circ} \mathrm{C}\right)$ & $\mathrm{T}_{\mathrm{s}}\left({ }^{\circ} \mathrm{C}\right)$ & $\mathrm{T}_{\mathrm{f}}\left({ }^{\circ} \mathrm{C}\right)$ \\
\hline 1 & 292 & 897 & 443 & 1411 & 504 & 1412 \\
\hline 2 & 304 & 945 & 473 & 1667 & 538 & 1600 \\
\hline 3 & 275 & 912 & 462 & 1512 & 528 & 1575 \\
\hline 4 & 321 & 950 & 485 & 1597 & 555 & 1620 \\
\hline 5 & 301 & 996 & 447 & 1602 & 534 & 1624 \\
\hline 6 & 288 & 976 & 461 & 1492 & $\mathrm{NR}^{*}$ & $\mathrm{NR}^{*}$ \\
\hline 7 & 322 & 963 & 449 & 1650 & 561 & 1591 \\
\hline 8 & 298 & NR & - & - & - & - \\
\hline Average & 300 & 948 & 460 & 1561 & 537 & 1570 \\
\hline SD & 15.94 & 34.69 & 15.15 & 92.91 & 20.39 & 79.68 \\
\hline
\end{tabular}

*NR - Not recorded, SD - standard deviation.

From temperature data, it was observed that initially it increases slowly and as the distance between flame front and thermocouple bead decreases, it increases sharply as thermocouple bead arrives to flame front and later on in flame zone for all compositions. Different propellants have different surface temperature and flame temperature. Surface temperature for DBP lies in the range of $290-320^{\circ} \mathrm{C}$ whereas flame temperature is of the order of $1000^{\circ} \mathrm{C}$ (Alspach and Hall 1991 ; Sabadell et al. 1965; Yano et al. 1987). For composite propellant surface temperature was found in the range of $440-490{ }^{\circ} \mathrm{C}$ and flame temperature was found in the range of $1400-1600^{\circ} \mathrm{C}$ (Alspach and Hall 1991; Sabadell et al. 1965; Yano et al. 1987). The composition with energetic binder and Zr has higher surface temperature in the range of $500-550{ }^{\circ} \mathrm{C}$ whereas flame temperature is comparable to composition 2. 
Table 3. Computed parameters for different compositions.

\begin{tabular}{|c|c|c|c|c|c|c|}
\hline \multirow{2}{*}{ Test No. } & \multicolumn{2}{|c|}{ Composition 1} & \multicolumn{2}{|c|}{ Composition 2} & \multicolumn{2}{|c|}{ Composition 3} \\
\hline & {$[d T / d x]_{s}$} & {$[d T / d x]_{g}$} & {$[d T / d x]_{s}$} & {$[d T / d x]_{g}$} & {$[d T / d x]_{s}$} & {$[d T / d x]_{g}$} \\
\hline 1 & 122.93 & 104.2 & 566.41 & 736.9 & 345.7 & 345.1 \\
\hline 2 & 112.2 & 136.0 & 568.53 & 880.2 & 298.8 & 392.6 \\
\hline 3 & 109.6 & 137.9 & 578.23 & 767.3 & 350.2 & 401.5 \\
\hline 4 & 125.3 & 130.2 & 582.91 & 842.7 & 294.7 & 365.2 \\
\hline 5 & 106.9 & 145.1 & 550.30 & 821.6 & 324.1 & 378.1 \\
\hline 6 & 113.2 & 116.4 & 573.24 & 864.2 & $\mathrm{NR}^{*}$ & $\mathrm{NR}^{*}$ \\
\hline 7 & 120.7 & 132.1 & 545.70 & 790.9 & 350.2 & 399.4 \\
\hline 8 & 131.0 & - & - & - & - & - \\
\hline Average & 117.73 & 128.84 & 566.47 & 814.82 & 328.91 & 378.15 \\
\hline SD & 8.48 & 13.97 & 13.85 & 52.34 & 23.74 & 20.94 \\
\hline
\end{tabular}

*NR - Not recorded, SD - standard deviation.

\section{FLAME STRUCTURES}

Propellant burning was captured using high-speed camera and stills extracted from video for all three type of propellants are depicted in Figs. 6, 7 and 8.

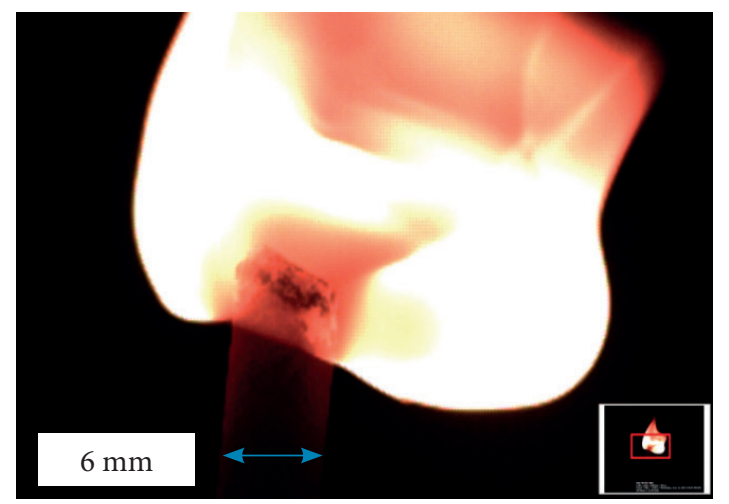

Figure 6. DBP Flame.

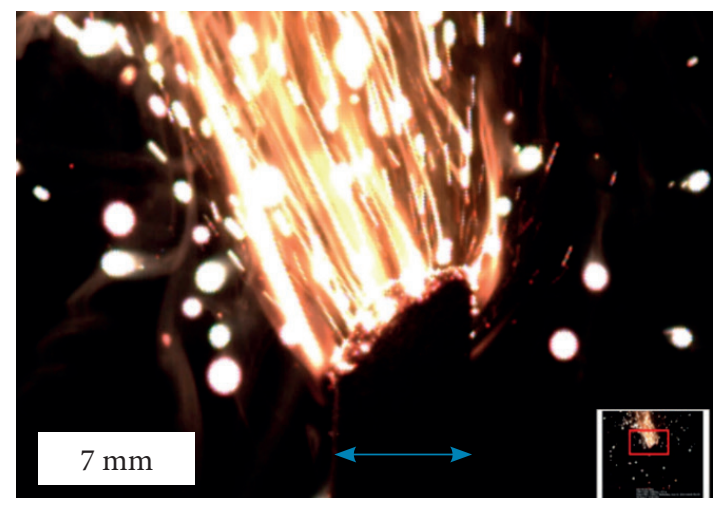

Figure 7. Composite propellant flame. 


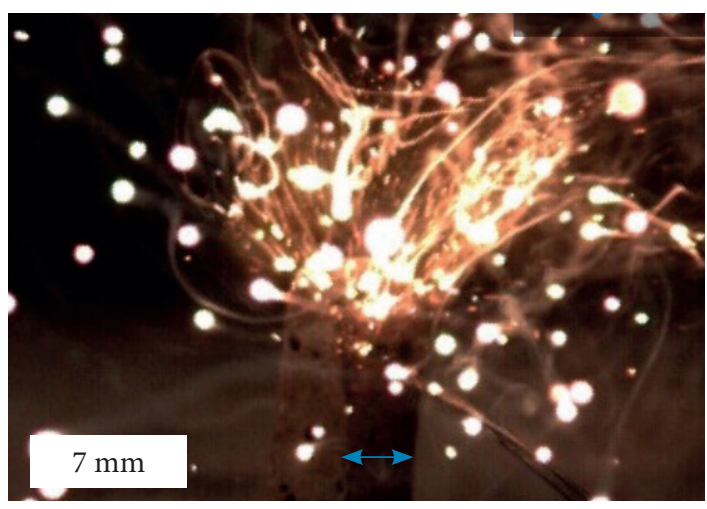

Figure 8. Composite propellant with energetic binder flame.

High-speed camera images and video for DBP clearly shows a candle like flame with low velocity. Also, a clear longer preheat zone, melt layer formation and non-glowing black zone are visible. For CP, aluminium particles are ejected out of the surface after ignition at surface level and a complete combustion of Al-particles takes place out of the propellant surface. A poor surface propagation of flame front, burning surface profile change and flame projecting out are also observed. A clear premixed flame in glowing zone is visible in the images. Same phenomenon is observed for CP with energetic binder along with melt layer of binder, Zr and HMX. A MATLAB based image processing tool was used for determination of reaction zone thickness. Samples thickness was taken as reference and then pixel by pixel computation was performed using image tool. Reaction zone thickness is found approximately $2-3 \mathrm{~mm}$ for DBP, $0.4-0.6 \mathrm{~mm}$ for composite propellant and 1.5-2.0 $\mathrm{mm}$ for composite propellant with energetic binder and HMX. Thickness of reaction zone is comparable to reported values.

\section{MICROSCOPIC OBSERVATIONS}

Figure 9(a) shows clear homogeneous sample surface with some layers. After quenching clear melt layers are observed on the surface along with some microcracks as visible in Fig. 9(b). These microcracks may be generated due to burning or quenching by water jet. Composite propellant (Fig. 9c) surface shows that polymer/binder has arrested metal and oxidizer crystals. Melt layers and partial burned particles are visible in quenched sample surface (Fig. 9d). Particle size was significantly reduced whereas porosity was increased and craters were formed on the surface. It ascertained that metals particles comes out from surface after ignition at surface which was observed in high-speed imaging. Composite propellant with energetic binder, Zr and HMX wide distribution of particles/crystals. These particles are very well bonded with polymer matrix (Fig. 9e). After burning, the quenched samples have melt layers and reduction of particle size. Lesser amount of melt layers is observed in the CP with energetic binder composition than the CP. It is due to the energetic binder also take part in the reaction and decomposition is at higher rate. This melt layer is a mixture of HMX and the binder.

These observations inferred that for DBP with DEGDN and DNT combustion mechanism is similar to NC and NG based DBP whereas CP and CP with energetic binder and HMX have completely different combustion mechanism. Craters are formed from gases being released below the surface materials and elevate the surface for CP compositions. 

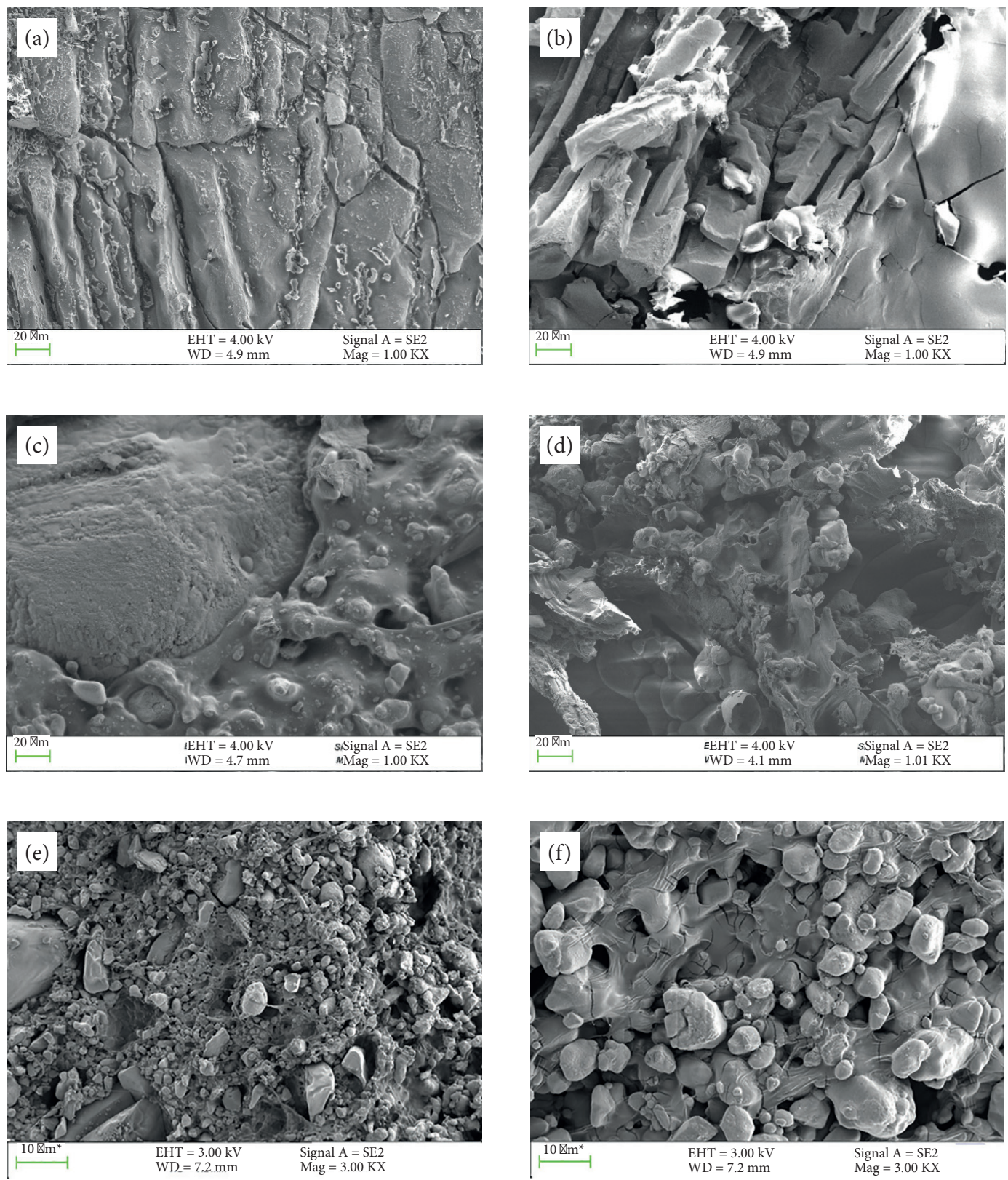

Figure 9. (a), (b) Double-base propellant, (c), (d) composite propellant and (e), (f) CP with energetic binder and HMX.

\section{CONCLUSION}

A successful attempt was made to study the combustion wave of different compositions at ambient pressure. It is clear that DBP with DEGDN and DNT gives the surface temperature in the order of $290-320^{\circ} \mathrm{C}$ whereas composite propellant has $440-490^{\circ} \mathrm{C}$ and composite propellant with energetic binder have the same order of surface temperature in the range of $500-5500^{\circ} \mathrm{C}$. Maximum flame temperature for DBP was found $\sim 1000^{\circ} \mathrm{C}$ and composite propellant and with energetic binder in the order of $1400-1600{ }^{\circ} \mathrm{C}$ at ambient pressure conditions. Standard deviation computed and found for surface temperature $<4 \%$, flame temperature $<6 \%$ and heat transfer rate slope in condensed phase $<7 \%$ and gas phase $<10 \%$. Also, the reaction zone thickness 
for DBP was found in the order of 2-3 mm, but it reduces for composite propellant $\sim 0.4-0.5 \mathrm{~mm}$ and CP with energetic binder and HMX, it is more than the CP and found in the order of $1.5-2 \mathrm{~mm}$. Heat transfer rate in condensed and gas phase is higher for $\mathrm{CP}$ than the two other compositions. DEGDN, DNT based DBP and CP with energetic binder, Zr and HMX have almost similar heat transfer rate in condensed and gas phase. Scanning electron microscope of the unburned and quenched sample provides insight of the combustion phenomenon for these compositions.

Burning surface significantly changes the surface morphology of $\mathrm{CP}$ and $\mathrm{CP}$ with energetic binder. It is in agreement with the fact that higher heat release at surface due to higher surface temperature, which is evident in the present experiments. Also, lesser melt layers provide decomposition or reaction faster in CP with energetic binder, which has higher burning rate than other two compositions. These observations are supported by available literature and have an application in the development of better combustion model and understanding of the phenomenon.

\section{ACKNOWLEDGMENTS}

The authors acknowledge Director HEMRL for permitting to publish this work. Authors also thankful to Shri DK Kankane for his continuous support and guidance. Editors and authors are thankful to Fundação Conrado Wessel for providing the financial support for publishing this article.

\section{AUTHOR'S CONTRIBUTION}

Conceptualization, Kalal RK and Shekhar H; Methodology, Kalal RK, Alegaonkar PS and Pande S; Investigation, Kalal RK, Shekhar H and Alegaonkar PS; Writing - Original Draft, Kalal RK; Writing - Review and Editing, Shekhar H; Resources, Pande S; Supervision, Shekhar H.

\section{REFERENCES}

Alspach DA, Hall GM (1991) Temperature profile measurements in solid propellant flames. In: 27th Joint Propulsion Conference. Sacramento: Meeting Paper. https://doi.org/10.2514/6.1991-2192

Boggs TL, Zenin BT (1978) Experimental diagnostics in combustion of solids. New York: Progress in Astronautics and Aeronautics AlAA Inc. https://doi.org/10.2514/4.865374

Derr RL, Boggs TL (1970) Role of scanning electron microscopy in the study of solid propellant combustion:* Part III. The surface structure and profile characteristics of burning composite solid propellants. Combust Sci Technol. 1(5):369-384. https://doi. org/10.1080/00102206908952217

Kenneth KK, Summerfield M (1984) Fundamentals of solid-propellant combustion. New York: American Institute of Aeronautics and Astronautics. v. 90.

Kubota N (1981) Combustion mechanisms of nitramine composite propellants Symp Int Combust. 18(1):187-194. https://doi. org/10.1016/S0082-0784(81)80023-9

Kubota N (2002) Propellants and explosives - thermochemical aspects of combustion. 3rd ed. Weinheim: Wiley-VCH.

Kuo KK, Summerfield M (1984) Fundamentals of solid propellant combustion. New York: AlAA Progress in Astronautics and Aeronautics.

Melcher JC., Krier H, and Burton RL (2001) Burning aluminum particle inside a laboratory-scale solid rocket motor. In: 37th AIAA/ ASME/SAE/ASEE Joint Propulsion Conference and Exhibit. Salt Lake: https://doi.org/10.2514/2.5977

Miller MS (1990) BRL-MR-3819, An evaluation of imbedded thermocouples as a solid-propellant combustion diagnostic. Maryland: Ballistic Research Laboratory Aberdeen Proving Ground. 
Sabadell AJ, Wenograd J, Summerfield M (1965) Measurement of temperature profiles through solid-propellant flames using fine thermocouples. AIAA J. 3(9):1580-1584. https://doi.org/10.2514/3.3212

Powling J, Smith WAW (1962) Measurement of the burning surface temperatures of propellant compositions by infra-red emission. Combust Flame. 6:173-181. https://doi.org/10.1016/0010-2180(62)90087-1

Sabadell AJ, Wenograd J (1963) AD0422387. The measurement of the temperature profiles of burning solid propellants by microthermocouples. Defense Technical Information Center. Alexandria: Unclassified.

Yano Y, Miyata K, Kubota N, Sakamoto S (1987) Combustion wave structure of AP composite propellants. Propellants Explos Pyrotech. 12(4):137-140. https://doi.org/10.1002/prep.19870120407

Yao EG, Zhao FQ, Xu SY, Hu RZ, Xu HX, Hao HX (2014) Combustion characteristics of composite solid propellants containing different coated aluminum nanopowders. J Adv Mater Res. 924:200-211. https://doi.org/10.4028/www. scientific.net/AMR.924.200

Yong L, Luoxin W, Xinlin T, Songnian L (2010) An SEM and EDS study of the microstructure of nitrate ester plasticized polyether propellants. J Serb Chem Soc. 75(3):396-376. https://doi.org/10.2298/JSC090326007L

Zarko VE, Kuo KK (1994) Critical review of methods for regression rate measurements of condensed phase systems , Non-intrusive Combustion Diagnostics. Int J Energetic Mater Chem Propul. 3(1-6):600-623. https://doi.org/10.1615/ IntJEnergeticMaterialsChemProp.v3.i1-6.590 